\title{
Teaching Innovation and Practice of Communication Principle Course
}

\author{
Changzhi Wei ${ }^{a,}{ }^{*}$, Xiaoqing Jiang ${ }^{b}$, Yue Zhao ${ }^{c}$, Lingyin Wang ${ }^{d}$, Qing Su \\ School of Information Science and Engineering, University of Jinan, Jinan, China

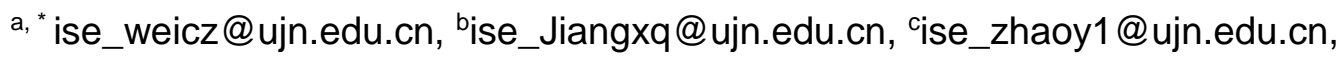 \\ dise_wangly@ujn.edu.cn, eise_suqing@ujn.edu.cn
}

\begin{abstract}
Communication principle course is the core basic professional course of communication engineering major. It is theoretical and practical very much. Because boring and difficult to learn, it is easy to become a "bird course". By reshaping the course content with the main line of "system" and "connection", the Trinity course education scheme is established, including the professional knowledge based on connection view, multi-dimensional practical exercise, and quality improving integrated with ideological and political education in courses. The results of feedback survey show that the reformed teaching of communication principle course has achieved good effect.
\end{abstract}

Keywords: Communication Principle; Teaching Innovation; Practice.

\section{Introduction}

Communication principle course is the most important basic course for electronic information majors. It serves as a connecting link between the preceding and the following. It is based on physics and mathematics, horizontally connects with other basic professional courses, and upward serves as the introductory knowledge of various professional courses, to connect the whole professional knowledge system into an organic whole. However, students generally reflect that the content of this course is boring, difficult and the teaching effect is poor [1].

Through long-term teaching practice and a large number of student investigation, the course team summarizes the main reasons for the "difficulty" of this course. First, most of the students have forgotten the large amount of mathematical-knowledge used in the course. The second is they learned the mathematical model but do not know the relationship, and lack a strategic view of the system. Third, knowledge points cannot be formed a system and are forgotten quickly. As a result, the most important core course of this major has become the most terrible course for students, so it is easy to become a "bird course" [2]. How to use advanced teaching ideas, optimize teaching objectives, design teaching contents, innovate teaching methods, reform assessment methods, and promote learning revolution has become the primary problem of teaching innovation of communication principle course.

\section{Teaching Reform and Innovation}

\subsection{General Idea}

In order to give full play to the core role of the course in professional teaching, the course team has discussed the ways to cultivate knowledge, ability and quality in classroom teaching, and gradually formed a teaching concept of mastering theory, exercising ability, improving quality, and cultivating students' comprehensive ability to solve complex problems and advanced thinking. By reshaping the course content with "system" and "connection" as the main line, the course team have established the trinity course education scheme, which includes professional knowledge teaching based on the concept of connection, the cultivation of practical ability in the whole process with multidimensional integration, and quality improving integrated with ideological and political education in courses, as shown in Fig. 1. 
Volume 3 (2021)

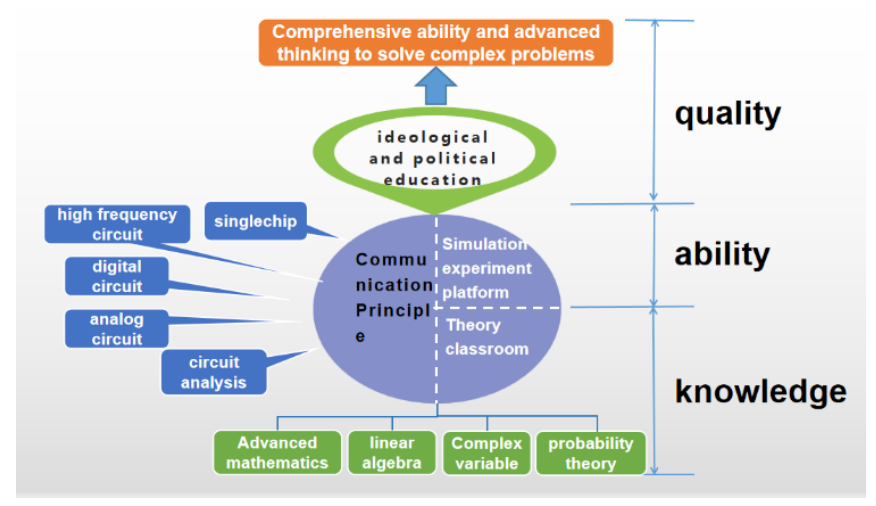

Fig 1. The trinity course education scheme

\subsection{Main Initiatives}

\subsubsection{Reconstruct the Professional Knowledge System based on "System" and "Connection"}

Regarding the communication system as the main line, the course team builds the connection teaching between communication principle course and the basic mathematics courses, professional basic courses and professional courses. The knowledge points in communication principle course involve many aspects, such as random signal analysis, channel characteristics, modulation and demodulation, coding and decoding. These knowledge points are the components of a point-to-point communication system. In the process of teaching knowledge, the course team always grasps this main line of the system, to realize the connection teaching between the knowledge points of this course. Students can understand "why" of the learned knowledge, and it is not easy to be forgotten.

Table 1. Connection teaching between communication principle and mathematics course

\begin{tabular}{|c|c|c|}
\hline $\begin{array}{l}\text { Mathematics } \\
\text { Course }\end{array}$ & Mathematical knowledge & Communication application \\
\hline \multirow{5}{*}{ Probability theory } & $\begin{array}{l}\text { Distribution of random } \\
\text { variables } \backslash \text { probability density } \\
\text { function }\end{array}$ & $\begin{array}{l}\text { Narrowband random process } \\
\text { anti noise performance of base-band signal } \\
\text { anti noise performance of 2FSK } \\
\text { optimal reception criteria }\end{array}$ \\
\hline & $\begin{array}{l}\text { Joint } \backslash \text { edge probability density } \\
\text { function }\end{array}$ & $\begin{array}{l}\text { Probability density of random envelope and random } \\
\text { phase in narrowband process }\end{array}$ \\
\hline & $\begin{array}{l}\text { Numerical characteristics of } \\
\text { random variables }\end{array}$ & $\begin{array}{l}\text { Stationary random process } \\
\text { stationary random process passes through linear system } \\
\text { narrow-band random process }\end{array}$ \\
\hline & Statistical average & $\begin{array}{l}\text { The definition of information entropy } \\
\text { the statistical average of phase-dependent signals } \\
\text { the channel capacity of discrete channels, and the anti } \\
\text { noise performance of } 2 \mathrm{ASK}\end{array}$ \\
\hline & Gaussian random variable & Gaussian random process \\
\hline \multirow{3}{*}{$\begin{array}{l}\text { Advanced } \\
\text { mathematics }\end{array}$} & Calculus & $\begin{array}{c}\text { Definition of digital characteristics of random process } \\
\text { principle of analog frequency modulation and phase } \\
\text { modulation } \\
\text { anti noise performance of } 2 \mathrm{PSK} \\
\text { signal to noise ratio of uniform quantizer }\end{array}$ \\
\hline & Fourier transform & $\begin{array}{l}\text { Stationary process power spectrum and auto- } \\
\text { correlation, analog modulation principle, digital } \\
\text { modulation principle, matched filter }\end{array}$ \\
\hline & Schwarz inequality & matched filter \\
\hline
\end{tabular}

Communication principle course uses a lot of mathematical knowledge. In model derivation, more attention should be paid to contact with advanced mathematics and probability theory at any time. 
Students should know what mathematical knowledge they are using and why they use it, and the connection teaching between communication principle and mathematics course is established, as shown in Table 1.

\subsubsection{Ability Training with Multi-dimensional Integration in the Whole Process}

The whole process refers to the classroom teaching - course experiment - course design directly related to communication principle course. Multi-dimensional refers to theory, system simulation, circuit simulation, circuit implementation and other levels. Integration refers to connect theoretical application in practical links [3].

In the classroom, the self-developed "classroom simulation teaching system" is used to realize function simulation. Through the system, students can know how to realize the mathematical model as a communication model, and can see the operation results of the communication model, to realize the connection from theory to practice and transform the knowledge to ability. At the same time, the teacher will arrange system simulation tasks to enable students to use the existing functional modules to realize a basic sending and receiving system. After the system simulation, the circuit simulation and circuit implementation are infiltrated in the links of experiment and course design.

\subsubsection{Comprehensive Quality with Ideological and Political Education in the Course}

The core of comprehensive quality is the shaping of values. In course teaching, this shaping is reflected in the design of course thought and politics [4]. China's communication technology has made brilliant achievements from "following", to "chasing", and then to "Surpassing". A large number of such examples have been introduced into the course to stimulate students' patriotic enthusiasm. For example, combined with mobile communication knowledge, it is introduced that at present, in the global 5g standard necessary patent (SEP) statement, the share of Chinese companies accounts for $34 \%$ as a whole, ranking the first in the world. Students' national self-esteem, selfconfidence and pride are enhanced, then the national ambition is established [5].

The new model of ideological and political education in the course is innovated. In addition to integrating ideological and political elements in the course of lectures, new ideological and political models such as "small topic before class" and "comparison between China and foreign countries" have been created combined with the current situation of China and US. Students need to search the current situation of relevant technologies and then report it. This form makes students understand the latest national technological development, and improves the acceptance of ideological and political education in the course.

\subsubsection{Reform and Innovation of Teaching Organization}

Discussion teaching runs through the classroom and students become the main body of the classroom. Arranging the teaching place in the discussion classroom, and problem discussion is carried out throughout the classroom teaching. There are problems, thoughts, discussions, reports, questions and replies. The discussion topics are carefully designed, more attention is paid to the logical relationship between the discussion topics, and students' speculative ability and logical thinking ability are imperceptibly cultivated.

Rich network resources have been built to facilitate students' autonomous learning. The course team have built online courses on the super star platform. There are 49 teaching videos for more than 800 minutes, 60 non video resources and 200 exerciser topics. Students can use mobile phones and other terminal devices to preview, review and self-test anytime and anywhere. They can also discuss and communicate on a certain problem, learn from each other, and improve them.

Introduce mobile app to make the classroom lively. Adapt to the cognitive characteristics of modern young people, the course team reform the form of classroom organization, and introduce superstar learning app into the classroom. Colorful classroom activities such as sign in, on-site voting, shaking selection, rush answer, questionnaire and scoring make the classroom no longer dull and ensure that classroom teaching activities can attract students' attention from beginning to end. 
The process assessment of the course is realized by means of information technology. Due to the use of information-based means as classroom assistance, the whole process of autonomous learning and classroom learning such as student preview, interactive discussion, classroom questioning, group display, after-school homework and chapter test are recorded, which has become an important basis for process assessment. This process assessment method has changed the traditional practice of "cramming before the examination" and stimulated students' enthusiasm in learning.

Project homework and mind mapping. According to the teaching progress, the corresponding project-based homework will be arranged after the chapter learning is completed, and the students are required to use the learned knowledge to design the system by themselves, simulate and analyze the performance of the system. At the same time, students need to write a summary report and draw a mind map of the knowledge system. Through the rumination of theory-practice-theory, the sublimation of knowledge and the improvement of ability can be realized.

\section{Effectiveness of Reform and Innovation}

Through the follow-up survey of the first batch of graduates in 2020 who are implemented the program, the admission rate of postgraduate entrance examination is $88.2 \%$, far exceeding the average level of all. The result indicates that the students' communication professional theory is grasped firmly and their knowledge systems are complete. All students in the class have won scientific and creative awards such as electronic design competition and mathematical modeling competition, which shows that students' practical ability has been effectively improved and their creative thinking and innovation ability have been greatly exercised. In the final teaching evaluation, students generally believe that through the course learning, their personal knowledge, ability and comprehensive quality have been significantly improved, which fully shows that the students approve the teaching methods of the course. In 2018, the school supervisor supervised the classroom teaching of the course. Two supervisors fully affirmed the classroom teaching design, teaching methods, classroom atmosphere and teaching effect. All sub evaluation items were excellent and the general evaluation was excellent too.

\section{Acknowledgments}

This work is supported by No. J193, No. KCSZ2035, Teaching research project of University of Jinan.

This work is supported by University of Jinan.

\section{References}

[1] X.P. Wang, Z. Shen. Research on teaching reform and practice of communication principle in Colleges and Universities under the background of first-class undergraduate construction[J]. Journal of Higher Education, No. 32, pp. 8-11, September 2020.

[2] R. Geng, N. Ye, J. Liu. The Teaching of Communication Principle under "Double First-Class" Construction--Based on Mind Mapping [J]. Software Guide, Vol.19 No. 12, pp. 160-163, May 2020.

[3] L.Y. Chen, D. Li, Z. Fang, et al. Research on innovative teaching of communication principle course for electronic information specialty[J]. Science \& Technology Vision, No. 33, pp. 40-41, October 2020.

[4] J.J. Sun, B. Du, H.J. Zhang, et al. Research and Exploration on Ideological and political construction of communication principle course[J]. Computer Education, No. 01, pp. 85-88, January 2020.

[5] H.Y. Fang, X.H. Li, J. Zhu, et al. Exploration and practical research on course thought and politics in the teaching of "communication principle"[J]. Industry and Information Technology Education, No. 03, pp. 42-46, April 2021. 